colonies simulating those of $B$. typhosus were saccharose fermenters, so that the use of saccharose in a modified Endo medium enabled me to distinguish rapidly between them and those of 13 . typhosus. The principal organism forming these black colonies on the bismuth sulphite medium is present in most specimens of sewage, but has not so far been found by me in faeces. The chief characters of this organism, to which I have given the name of $B$. effuviei, are as follows: A Gram-negative actively motile bacillus with growth on agar resembling 3 . coli; in liquefying gelatin and in being negative to methyl red and giving a positive reaction to the Yoges-Proskauer test, it resembles $B$. cloacae, from which it differs in its reduction of sulphites and in being a non-lactose fermenter. It grows in Koser's citrate solution. It ferments glucose, maltose, mannite, saccharose, and starch, with the production of acid and gas, and has no action on lactose, dulcite, and salicin. It forms indol and digests inspissated serum.

The 3 . effluviei is probably related to the $B$. proteus group, although it ferments mannite and does not decompose urea.

Material Employed.

Crude fresh-screened sewage was taken from the combined sewage of the upper and lower level sewers of Belfast on its way to the sedimentation tanks. On three occasions the samples were taken at 10 a.m., on the fourth at 2 p.m. The sewage was flowing along and was taken up in a sterilo bottle, and may be regarded as representative of the ordinary dry weather sewage of Belfast. One sample taken on February 25th, 1928, gave the following figures on chemical analysis:

Free and saline ammonia

Parts per 100,000 .

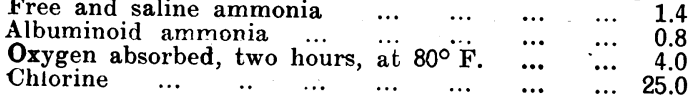

On bacteriological examination it showed 480,000 colonies per cubic centimetre on a MacConkey plate, and of these 218,000 were lactose fermenters and 262,000 non-lactose fermenters. It also contained 200 spores of B. welchii per cubic centimetre.

The chief details in connexion with the isolation of the typhoid bacillus may be summarized as follows:

TABLE I.

\begin{tabular}{l|c|c|c|c|c|c}
\hline Sewage. & Date. & $\begin{array}{c}\text { Amount } \\
\text { of : ewag } \\
\text { Planted } \\
\text { Out. }\end{array}$ & $\begin{array}{c}\text { No. of } \\
\text { Black } \\
\text { Colonies } \\
\text { Examined }\end{array}$ & $\begin{array}{c}\text { No. of } \\
\text { Saccharose } \\
\text { Fermenters. }\end{array}$ & $\begin{array}{c}\text { No. of Non- } \\
\text { saccharose } \\
\text { Fer- } \\
\text { menters. }\end{array}$ & $\begin{array}{c}\text { No. of } \\
\text { Typhoid } \\
\text { Colonies } \\
\text { Found. }\end{array}$ \\
\hline Belfast & \begin{tabular}{c|ccc}
1928. \\
Feb.16
\end{tabular} & 4 c.cm. & 21 & 27 & 4 & 4 \\
Eelfast & Feb. 25 & 11 c.cm. & 67 & 60 & 7 & 2 \\
Belfast & Mar. 8 & 10 c.cm. & 64 & 50 & 14 & 7 \\
Eelfast & Mar.12 & 5 c.cm & 71 & 56 & 15 & 8 \\
\hline
\end{tabular}

The examination of $30 \mathrm{c.cm}$. of sewage resulted in the isolation of twenty-one strains of $B$. typhosus. The baeilli were not uniformly distributed in the sewage, some of the plates yielding none and others several. Probably more bacilli were present than were isolated, and I am of opinion that at least one typhoid bacillus is present in each cubic centimetre of the ordinary crude screened sewage of Belfast.

Whether the sewage of other cities and towns would yield similar results requires investigation. I may state that Belfast, although at present comparatively free from typhoid fever, was at one time one of the most typhoidinfested cities of Europe, and consequently would be expected to have many typhoid "carriers." From the annual report of the superintendent medical officer of health for Belfast for 1926 I may take the following figures.

\begin{tabular}{ccccccrccc} 
Year. & \multicolumn{4}{c}{ Population. } & \multicolumn{4}{c}{$\begin{array}{c}\text { Deaths from } \\
\text { typhord fever. }\end{array}$} & $\begin{array}{c}\text { Annual enteric } \\
\text { mortality rate } \\
\text { per 10.000. }\end{array}$ \\
1897 & $\ldots$ & $\ldots$ & 310,000 & $\ldots$ & $\ldots$ & 354 & $\ldots$ & $\ldots$ & $\ldots$ \\
1898 & $\ldots$ & $\ldots$ & 340,600 & $\ldots$ & $\ldots$ & 640 & $\ldots$ & $\ldots$ & 18.4 \\
1901 & $\ldots$ & $\ldots$ & 350,862 & $\ldots$ & $\ldots$ & 341 & $\ldots$ & $\ldots$ & 18.8 \\
1905 & $\ldots$ & $\ldots$ & 369,000 & $\ldots$ & $\ldots$ & 128 & $\ldots$ & $\ldots$ & 3.7 \\
1911 & $\ldots$ & $\ldots$ & 386,449 & $\ldots$ & $\ldots$ & 15 & $\ldots$ & $\ldots$ & 0.4 \\
1920 & $\ldots$ & $\ldots$ & 413,000 & $\ldots$ & $\ldots$ & 34 & $\ldots$ & $\ldots$ & 0.8 \\
1926 & $\ldots$ & $\ldots$ & 416,000 & $\ldots$ & $\ldots$ & 6 & $\ldots$ & $\ldots$ & 0.1
\end{tabular}

During 1926 there were 84 cases of enteric fever notified in Belfast. It would seem, therefore, that in a town that has been exposed to outbreaks of typhoid fever the ordinary sewage contains the typhoid bacillus, and that the sanitary policy which aimed at the formation of a clean environment-pure water, pure soil, and the rapid removal of excretal matter from premises-was sound. In such a town our results show that the specific infective agent is liable to be present in ordinary sewage. Nearly all the cases of typhoid fever notified are treated in an isolation hospital, the sewage of which, before discharge into the city sewers, is sterilized by steam; of the 84 patients with enteric fever in Belfast in 1926, 82 were treated in hospital. The source of the baeilli in the sewage is therefore probably mainly " carriers." While the bacilli remain in the sewage as such there is little danger of infection, but there is the possibility of the return of the typhoid bacillus to man again by contamination of the soil, by leaking drains and sewers, by contaminated water supplies, and by the consumption of shellfish living on. sewage-polluted foreshores.

The facts relating to the isolation of $B$. typhosus from shellfish collected from Belfast Lough foreshore at Greencastle are as follows. On March 6th seven cockles were opened; the liquor was collected on a sterile Petri dish and was then transferred to nino plates of the special bismuth medium. Nine black colonies were studied, seven being saccharose fermenters and two non-saccharose fermenters; of the latter one proved to be $B$. typhosus.

The bacilli which I regard as being typhoid bacilli were actively motile and Gram-negative; they formed acid but no gas in glucose, maltose, and mannite agar shake cultures. No fermentation of lactose, saccharose, dulcite, and salicin occurred; indol was not formed, and gelatin was not liquefied.

The bacilli were. agglutinated to full titre by four different antityphoid serums, and were not agglutinated by normal serums in dilutions of 1 in 20 . That the organisms were typhoid bacilli was established by means of absorption tests. It was found that those recovered from the sewage and the cockles removed from several antityphoid serums the agglutinins acting on them and on genuine typhoid bacilli.

REPERENCES.
1 Houston, A. C. (1914) : Tenth Report on Research Work to Metropolitan Water Board. ${ }^{2}$ Wilson, W. J., and Blair, E. M. McV. (1927): Jomrn. of
Hygiene, 26, 374. ${ }^{3}$ Adams, B. A. (1928): The Medical Officer, 39, 185 .

\section{A CASE OF PROGRESSIVE MUSCULAR ATROPHY OF THE PERONEAL TYPE;}

Twenty-one of the Patient's Relatives being also AFFECTED.

BY

GEORGE PARKER, M.A., M.D., CONSULTING PHYSICIAN, BRISTOL GENERAL HOSPITAL.

This syndrome was recognized as a distinct type, first by Charcot and Marie in 1886, and independently by Sir Howard Tooth in a thesis the same year. Several cases which wero perhaps similar had been recorded previously, such as Osler's Star family in New York, and Meryon's patient in 1852. Herringham, in 1887, published an account of a family where eighteen members were all affected, Symonds brought forward one where nine suffered, Collier one with eight, while Beevor, Bryant, Ormerod, and Schuitzo have each reported families with threo cases.

The disease is transmitted both in the male and in the female line; and there is not the great preponderance of males affected that we get in pseudo-hypertrophic paralysis. As Williams has remarked, however, there are instances where no relatives are affected, and others whero several brothers and sisters develop the disease simultaneously for the first timo in a family. It has several times appeared after a febrile disease, such as measles. It may commence in childhood, more often in the second or third decade. Generally the first wasting is seen in the feet or peronei on both sides, but occasionally it shows itself first in the hands 
and forearms. The wasting and weakness extend very gradually to the upper segments of the limbs, and the muscles of the trunk and face are rarely affected even after thirty or forty years. Bulbar symptoms are unknown. It is important to notice that the reaction of degeneration can be found in some of the muscles in practically every case, while there may or may not be cramps, pains, coldness and lividity of the skin, fibrillary tremors, or slight sensory changes. My patient, F. J., aged 33, married, with one child, is a strong
and otherwise healthy man, in whom the condition first appeared when he was 19 years old. He was then an active footballer and when he was 19 years old. He was then an active footballer and
member of a rowing club. He even now plays golf and finds no member of a rowing club. He even now plays golf and finds no
fatigue from a five-mile walk, though the disease has progressed steadily. The feet were first affected and then the hands and forearms followed. There is no history of any previous illness, and he has rarely required medical treatment. The great age which many of his relatives attained, even when affected like himself is striking. His heart, kidneys, and lungs are normal, the expansion of of lips. The action of the bladder and bowels is normal. There is extreme wasting of the muscles of the feet and lower part of the cxtreme wasting of the muscles of the feet and lower part of the
legs, and intrinsic muscles of the hands, and the forearms, and legs, and intrinsic muscles of the hands, and the forearms, and
slightly of the thighs. There is no movement at all in the toes or at the ankles; neither abduction nor adduction or flexion of the feet. The great toe and the others are flexed and quite motionless; the arch of the foot is preserved, and his gait in walking is surprisingly good, though slightly high-stepping. flexes and extends the leg on the thigh and the thigh on the hip freely, but in getting up from the ground he likes a little assistance, such as putting his hand on his thigh, but he can beend ance, such as putting his hand on his thigh, but
down to touch the ground and rise up again easily.

down to touch the ground and rise up again easily.
Though the small muscles of the hands are so wasted, the grip is strong, and he has no difficulty in buttoning his clothes or in writing. Supination and pronation have escaped, but extension at the wrist is weak, and the hands when at rest take the claw form. There is little or no fibrillation or muscular irritability on percussion. There is no ataxy. He stands easily with his eyes shut, and the pupils react to light The knee-jerks are present, but weak. the Achilles tendon-jerk is present, but there is no plantar reflex or clonus: sensation to light touch or pin-prick appears normal over hands, feet, and trunk. There is no reaction to either current in feet, calves, or hands, but some of the extensors at the wrists show resction of degeneration-that is, no faradic reaction but good galvanic, with the positive pole equal to or greater than the negative.

In this patient, then, we get wasting of the distal segments of the limbs with loss of power, beginning in early adult life and steadily progressing. The reflexes are diminished and reaction of degeneration is present. Finally, it appears from his statements that eleven males and ten females of his family are similarly affected. In this family the first case recorded is that of the patient's great-grandfather, and out of fifty-four of his descendants twenty-one are already affected and others are not ret old enough. The disease seems to pass rather more readily by the male line than the female; and it has little effect on the duration of life. In a group of five brothers and sisters affected, two are alive aged 77 and 79 , and three died at ages of 62,82 , and 86 .

One wonld like to know whether the affection did actually begin with the great-grandfather. It cannot have existed many generations back at the present rate of increase, for the district would be full of cases; whereas the disease is always a rare one.

The type is clearly distinct from the myopathies. Thus(1) Pseudo-hypertrophic paralysis has neither the distal distribution of wasting nor the reaction of degeneration, and it generally show's some muscles enlarged.

(2) The rare cases of distal myopathy. such as the one recorded by Gowers ${ }^{1}$ appear to have the facial muscles involved and no reaction of degeneration.

(3) The Werdnig-Hoffmann type is really myelopathic, but the wasting begins in the proximal segments during the second and third years of life, and death usually follows in three or four years. Reaction of degeneration is found in these cases, and several may occur in one family.

(4) In amyotonia the trouble begins at birth or soon after. There is no definite wasting, but paresis of the distal segments which may improve if the patient survives. I think there is no affection of other members of the family here, but reaction of degeneration may be present.

My groul of symptoms, then, differs widely from all these. The pathology of this peroneal type does not seem to have been made much clearer of late. The sclerosis in the columns of Goll and Burdach, and the lesions in the anterior horn cells and in the peripheral nerves, appear to vary in intensity in different cases, but we are completely ignorant of the rause which produces them. Whether it be "a developmental weakness, an inherited susceptibility to some toxin," or a true infection, spirochaetal or otherwise, remains to be proved.

REFERENCE.

I British Medical Journal, 1902, ii, p. 89.

\section{PARALYSIS OF ALL FOUR LIMBS CURED BY REMOVAL OF A SPINAL TUMOUR.}

BY

\author{
WALTER BROADBENT, M.D.CANTAB., F.R.C.P., \\ SENIOR PHYSICIAN, \\ AND
}

G. W. BERESFORD, O.B.E., F.R.C'S.,

ASSISTAN' SURGEON, ROYAL SUSSEX COUNTY HOSPITAL.

A Womsar, aged 51, was admitted to hospital in October with complete paralysis of the right arm and leg and partial paralrsis of the left arm and leg. She also complained of intense headache and gnawing and shooting pains in both arms; these were so severe that hypodermic morphine was needed to give her any sleep.

The history given was that fourteen months previously she had first noticed numbness in the right hand, but this did not bother her until in February she tripped over something and had a bad fall, which shook her considerably. After that she began to lose the use of her right arm. By May the arm was so weak that she had to give up her work, and she was beginning to drag the right foot. There was also then some aching pain in the shoulders and right arm. Early in $J$ uly the right hand had become uscless, and the trouble in the right leg had advanced so much that she could not walk, also the left leg was affected. By the end of August the right arm and leg wers paralysed, and she could only move the left leg slightly, and there was weakness in the left shoulder.

On admission the right arm and leg were motionless; she could draw up the left leg slightly as she lay in bed. She could not abduct the left shoulder, but could adduct and rotate it, and flex the forearm. The grasp of the hand was very weak, and she could not feed herself with it. Both the trapezii were wasted, but not the arm muscles. Reflexes were increased.

She complained of intense headache and agonizing shooting and aching pains in both shoulders, and of "pins and needles" all over the body. The pain had been getting worse and worse for the past six weeks. There was anaesthesia of the right hand and forearm, and diminished sensation in the same area on the left arm. Sensation over the legs and body was less than normal, and distinction between heat and cold was not accurate. There was no incontinence, but it was difficult to get the bowels to act.

The neck could be rotated and flexed, and an $x$-ray photograph showed no disease of the bones. On lumbar puncture the cerebro-spinal fluid was not under pressure. It contained globulin in large excess, colloidal gold 55544,33221 , Fehling reduced normally, no increase of cells. The Wassermann reaction was negative. The cerebro-spinal fluid of the cisterno puncture contained only a very faint trace of globulin, colloidal gold 01110,00000 , no cells. It would be interesting to know if this striking difference in the cerebro-spinal fluid below and above the tumour occurs in other cases.

The diagnosis made was a lesion of the spinal cord about the level of the second cervical vertebra, and, on account of the intense pain, probably a tumour in the meninges pressing on the back of the cord. Mr. Beresford was asked to do a cisterno puncture and insert some lipiodol. Y-ray photographs after this showed some lipiodol just above the level of the first cervical, and opposite the level of the first and second cervical vertebrae.

After the operation the movements of the left arm soon began to improve, next those of the left leg. It was nearly a month before the right leg showed signs of recovery, and the right arm later still. Massage and 